11. N. V. Isagulov. Intermedial'nost' kak zontichnyj termin: popytka klassifikacii [Intermediality as an umbrella term: an attempt to classify]. Kul'tura slova [Word culture] № 1 (2) (2019), pp. 28-39.

12. A. N. Lavrent'ev. Istoriya dizajna: uchebnoe posobie [Design history: a textbook]. Gardariki, Moscow (2007).

13. M. V. Gavrilova. Social'naya semiotika: teoreticheskie osnovaniya i principy analiza mul'timodal'nyh tekstov [Social semiotics: theoretical foundations and principles of analysis of multimodal texts]. Politicheskaya nauka [Political studies]. № 3 (2002), pp. 101-117.

14. O. V. Aronson. Obrazy informacii. Vliyanie Interneta na soznanie i strukturu znaniya [Images of information. The influence of the Internet on consciousness and the structure of knowledge]. IF RAN, Moscow (2004), pp. 131-161.

15. A. A. Denikin. Telesno-orientirovannyj podhod pri analize proizvedenij ekrannogo iskusstva [Body-oriented approach in the analysis of works of screen art]. Znanie. Ponimanie. Umenie [Knowledge. Understanding. Skill]. № 2 (2017), pp. 115-131.

16. T. Parsons. O strukture social'nogo dejstviya [About the structure of social action]. Akademicheskij Proekt, Moscow (2002).

17. T. Parsons. Toward a general theory of social action. Routledge; Abridged Edition (January 31, 2001).

DOI 10.15826/B978-5-7996-3081-2.25

\title{
Use of New Nature Texts in the VKontakte Social Network
}

\section{Gudova Margarita', Glazkova Daria²}

${ }^{1}$ Ural Federal University, Ekaterinburg, Russia

${ }^{2}$ Ural Federal University, Ekaterinburg, Russia

Corresponding author: Glazkova Daria, dio.di.2d@gmail.com

Abstract. Multi-modal or multi-code texts are an important part of modern communicative culture. Frequently, specific feature of this culture could be determined through the creation and usage of such texts. As T. G. Galaktionova, we prefer calling such texts as "new nature" texts and consider their features and 
analyze the case of using them in the social network communication. In the conclusion we prove that in such a case the "new nature" texts are dominant due to their emotional expressiveness.

Keywords: multi-code texts, multi-modality, new nature texts, social network, VKontakte

\section{Introduction}

Communication via the Internet is a unique and complex phenomenon that reflects the life of modern society. Likewise a real life communication, communication via the Internet tends to be emotional, and it is reflected in the use of polycode and polymodal texts by communicants.

The usage of the "new nature" texts is a distinctive feature of Internet communication messages. By calling such communication "Internet communication", we emphasize both the channel, through which the message is transmitted, and the context in which the communication is taking place. And, at the same time, we are not highlighting a devise used to commit the communication, as is the case with terms "computer communication" or "computer-mediated communication".

We understand Internet communication as the process of exchanging polymodal and/or polycode information via the Internet. For this process are compulsory the using of a special Internet discourse and thecommunicators' feedback. The uniqueness of the Internet as a means of communication is that this network is the only one of its kind-a medium for communication including the using of different types of texts. Today, various systems of speech perception andgenerationare used for communication, eliminating the boundaries of usingdifferent modalities texts, and neutralizing the factors oftime and distance.

"New nature" texts are used in various types of communication: in mass communication (stories, live broadcasts) and in personal communication (stickers, emoji, voice messages, memes).

According to a study conducted by the Russian analytical company Mediascope "Social networks in numbers" [Mediascope, 2019], the first place in the rate of popularity in Russia is the social network tool Vkontakte, which is used by $72 \%$ of Internet users in Russia (38.1 million), the second place is the messenger WhatsApp - $61 \%$ (32.5 million), the third place is Instagram- $56 \%$ (29.6 million), and then YouTube- $45 \%$ (23.9 million); 
the $5^{\text {th }}$ and $6^{\text {th }}$ are Viber and Telegram messengers- $41 \%(21.8$ million $)$ and $21 \%$ (11.3 million).

Each of the mentioned above social networks and messengers are a complex set of programs that people use to communicate via the Internet. The user's ability to have multiple accounts (personal pages) in different applications makes it possible to send information from one application to another, which creates one large information complex.

\section{The purpose and hypothesis of the study}

The authors' attention is focused on the question what are the texts of a "new nature" - polycode and/or multimodal texts that users use to communicate on the Internet, especially in the case of young people's communication via the Vkontakte network (further "the VK").

The hypothesis of this study is formulated as followed: "new nature texts help young VK communicators to raise the emotional level of network communication".

\section{Research method and methodology}

The term "texts of a new nature" is very popular among the authors of the RSCI; this term is used in 364.856 scientific publications. The most influential publications belong to such authors as E. I. Kazakova [Kazakova, 2016, 102], Galaktionova T. G. [Galaktionova, 2016, 13], Zagidullina M. V. [Zagidullina, 2019, 181], Eiger G. V. [Eiger, 1974, 106] and others.

To investigate the use of "new nature" texts by young VK communicators, we will use the "involved observation" method. We will analyze the communication activity of the academic group chat in the VK (one of the authors is the participant of this chat), and after that we will describe the usage of the new nature texts and their functional significance.

Next, we introduce a scheme, through which we will analyze the communicative texts of a new nature. This scheme is inspired by the classification of creolized texts proposed by L. V. Dubovitskaya [Dubovitskaya, 2013, 14] and P. Celentin [Celentin, 2007, 36]. This scheme assumes consistent answers to the following research questions:

1. Short description (What is it?);

2. What social networks and/or messengers is this text used in?

3. The type of creolization and compositional complexity;

4. Presence of hypertext complexity (hyperlinks); 
5. Type of communication;

6. The degree of involvement of the addressee (minimal/ medium/ significant);

7. Communication goal (Why is it used by communicants?);

8. Communicative advantage (Why is it better than the regular printed text?).

\section{The main body of the research}

4.1.

To begin with, we will describe various genres of a new nature text, according to the schemementioned before. The texts for analysis were chosen by the author because of the frequency of their use in the VK.

Stories - photos or 10-second videos with text, emojies, stickers, and other handwritten notes. The key feature of such posts is that in comparison with regular posts in the feed, they are deleted after 24 hours. All popular social networks use this text (Facebook, Instagram, Vkontakte) and you can also find it on the YouTube video hosting service. The number of components in a story may differ depending on its communicative purpose. However, the story usually has a visual component (photo or video) and a verbal comment or a complex (verbal comment + Emoji). Stories can be personalized: you can apply filters and masks to a photo or video (filters that change your face), or it is possible to add an emoji or write something so that the audience can understand the mood of the author at the time of publication. According to the degree of compositional complexity, the story is a complex text, the degree of creolization of which can be assessed as "complementary" (the verbal message complements what was shown by the image, the codes complement each other).

Stories are used for oral (if it is a video story) or written (if it is a photo and text) one-to-many communication. Through stories, users are reminded of themselves in an unobtrusive manner. The plot of the story can be absolutely anything, but, as a rule, it is something that a person wants to focus the attention of their audience on: a new photo, a beautiful view, a cute pet, an interesting link. Therefore, hypertext complication is also possible. Thus, it can be argued that the story is an interactive text, since it requires the reader's direct participation (reaction to the story, reading/not reading the verbal text, visiting the author's page, etc.). It is also interesting that the story can be published by both individual users and communities. As soon as a user/ 
community publishes a story, it appears in a special block in the form of a circle with the user's photo highlighted.

Communication goal: attracting attention, narration. Communicative advantage: it reflects the mood of a person in a particular time, situational. With the help of caption-hints, the author manages to convey his idea to the recipientsmore accurately. If there is a hyperlink, the information content of the story increases, because the recipient of the message can click on the link to get more information.

Live - the function of video broadcasting in real time. As a rule, it is planned in advance and can take place in the format of a public monologue or dialogue. Each live broadcast has a chat where the audience can easily contact both the host of the broadcast and among themselves. The audience can also give feedback by clicking on the heart in the lower right corner of the screen. This function is available in Facebook, Instagram, VK. But it is not possible to conduct a Live in messengers.

This text has a complex composition, because it is video-verbal (contains visual and audio components). The degree of creolization of the live broadcast can be described as "parallel" (the verbal and non-verbal components are going simultaneously). By type of communication, this is the text of "one-to-many" and "many-to-one" mixed communication, since the verbal component is represented by the oral speech of the addressee and the written speech of the addressees giving feedback. The engagement of recipients is significant, because the feedback is instant. There is no hypertext complication in such texts, because hyperlinks cannot be attached.

The communicative purpose: the narrative, the exchange of information. Communication advantage: live dialogue in a real time.

Voice message - is a phrase recorded in real time (with all the noises). This tool is available in all social networks and messengers.

This is a text with zero creolization, because it is only text in audio format. The degree of compositional complexity is simple. However, it is noteworthy that by using this online communication tool, the communicator can accurately convey their emotions to the opponent by saying the message, rather than writing it. The degree of involvement is significant. This text is recorded for the one purpose - to be listened to. The text has no hypertext complexity.

A voice message is an oral communication text used in one-to-one or one-to-many written communication (if it is a chat). This is the most vivid representation of the oral-written nature of Internet communication, since 
the dialogue can take place in the format of "audio-question - written response". And the communication process will not be somehow complicated or interrupted.

Communication goal: information message. Communication advantage: allows the addressee to transmit more information with less effort.

A modification of the voice message is a video message -a phrase recorded on video. This tool is available only in Telegram. In general, it is a hybrid of a story and a voice message: a short video containing a couple of phrases. It is used as a voice message - one-to-one or one-to-many communication. It is a complex text, being a video-verbal message. The degree of involvement - significant. This text is recorded for the one purpose - to be listened to. The text has no hypertext complexity.

The communicative purpose: the narrative, the exchange of information. Communicative advantage: situational, allows transmitting more information, spending less effort.

Emoji - is the language of ideograms and emoticons used in emails and web pages, as well as the icons themselves. As a rule, emoji complement the text, because they are usually being used in written communication together with the verbal component. However, sometimes message could consist of only emojis component. It is usually a reaction to something and consists of one or two emojis repeated.

Emoji are used in all social networks and messengers, being perhaps one of the first ways to express emotions on the Internet. Messages containing them are used for one-to-one and one-to-many written communication. Such a text assumes minimal involvement of the addressee, because it is just a text that expresses the reaction of the interlocutor. Hypertext complexity is possible, because the emoji can be "turned into" a hyperlink.

Communicative purpose: the expression of emotions, economy of speech efforts. Communicative advantage: are helping to fulfill text with emotions and make communication more vivid.

With the enlargement of smartphone screens, it became possible to express emotions on a larger scale and due to this fact Stickers appeared - large graphic images that are helping to express emotions like emoji. These texts of a new nature are actively developing and are now becoming voluminous and animated.

Stickers can not only express emotions, but also reflect the interests and style of the person using them. Opposite to emoji, which are universal for 
everyone, there are a huge variety of stickers (the hero of a sticker set can be anything from people and animals to objects and fantastic creatures). It is noteworthy that stickers can contain not only an image, but also captions, which makes them a fully-fledged text

The use of stickers is similar to the use of emojis: they are used for one-to-one and one-to-many written communication. Such a text assumes minimal involvement of an addressee, because it is just an informative text that expresses the reaction of the interlocutor. However, the use of stickers is often intended to defuse an atmosphere and create a comic effect. Therefore, the emotions of the sticker characters are hypertrophied. Stickers can also copy memes, which makes it necessary to know the original meme, in order to understand correctly the message encoded in the sticker.

Returning to the analysis of the sticker as a communicative text of a new nature, it is worth noting that stickers are used in all social networks and messengers. The degree of creolization depends on the compositional complexity and can be characterized as complementary (if the sticker has a caption) or as zero (if the sticker contains just a picture). There is no hypertext complication.

Communication goal: expression of emotions, exchange of information. Communicative advantage: are helping to fulfill text with emotions and make communication more vivid, show the interests of the person using them.

Memes- any witty or ironic statements, pictures, videos, or sounds that have spontaneously gained popularity and are steadily distributed via the Internet. Since the variety of memes is huge, we will describe them only in general terms, highlighting two groups: pictorial memes and video memes.

Pictorial memes-captions, pictures or pictures with captions. The degree of creolization depends on the compositional complexity and can be characterized as "complementary" (if the meme consists of a picture and a caption) or as zero (if the meme contains just a picture or acaption). There is no hypertext complication.

Video memes - funny videos. It is a complex text that constitutes a video-verbal message. Hypertext complexity is possible because each video has a description where the hyperlink can be placed.

Using of memes is quite similar to using emojis and stickers: they are used for one-to-one and one-to-many written communication. Memes are used in all social networks and messengers. Like stickers, memes are used to make communication more vivid. However, the use of memes in communication 
has stylistic and status restrictions. The same is true for stickers basedon memes. Moreover, for communication to be successful, both communicants must know the meaning of the meme and understand the joke encoded in it. The use of video memes in communication is even more difficult, because it appeals to the sense of humor. Therefore, as a rule, communication using memes occurs between people who haveclose and friendly relationships. The recipient's engagement rate is average. This text is sent to the interlocutor in order to amuse him, and the opponent then reacts either positively or negatively.

Communication goal: the exchange of information, expression of emotions, saving speech effort. Communicative advantage: helping to fulfill text with emotions and make communication more vivid.

Based on this research, we can conclude that texts of a new nature are used in all types of communication: both in mass (history, live broadcast) and personal (stickers, emoji, voice messages, memes).

Such textscould be classified according to the compositional complexity. There are simple texts (with zero creolization) - voice messages, stickers without captions, and memes expressed only by an image or phrase; complex texts (consisting of 2-3 modules) - video messages, video memes, stickers and memes consisting of an image with a caption, and highly complex (consisting of many modules (may include simpler texts)) - stories and live broadcasts.

Based on our classification, we can conclude that texts of a new nature are used in communication to make it more vivid, and involving less speech effort.

4.2.

In this part, we will pay attention to the new nature texts used in oneto-one and one-to-many communication through the example of chats in the social network Vkontakte (further the VK).

To study the use of texts we used the method of quantitative content analysis. The author selected seven chats in the VK. The total array is 46001 message. The sample is solid.

In two chats out of seven there is communication of one-to-many type. These are the so-called "group chats": the classmates' chat and the friends' chat. These chats were selected by the following criteria: time (they were created at the same time), liveliness (people write often) and informal communication style. However, chats are not totally equal. The classmates' chat unites less familiar people and the communication purpose is the educational 
process, and the friends'chat unites people who are in a more close relationship, and the communication purpose here is the communication of people located in different cities.

The author selected all polycode messages from the two mentioned above chats; then their number was correlated with the total number of messages. The percentage of messages containing new nature texts is almost the same (even slightly higher in the chat of classmates). In this regard, we can conclude that the closeness of the interacting people does not affect the frequency of using new nature texts.

After that, the author analyzed and compared the types of new nature texts used in polycode messages and emojis were found to be the most popular way to emotionally enrich the written speech. It is quite remarkable that the closeness of communicators and the purpose of communication affects the variety of new nature texts. For example, in the chat of friends, all new nature texts of personal communication are used with almost the same frequency, and in the classmates' chat there were - mostly emojis, with no voice messages at all. In this regard, we can argue that emoji are the most neutral text of the new nature, which can be used regardless of the sphere of communication, while voice messages are used mostly while communicating with more close individuals.

Further, the author analyzed five personal chats with one-to-one communication using the same scheme. There were: chats with a colleague, chats with two male friends and two female friends. These dialogues were selected based on the frequency of communication.

As in the case of the two group chats, all polycode messages from the above five dialogs were selected first, and then their number was correlated with the total number of messages. As a result, it became clear that the percentage of polycode messages was approximately the same for all chats. It can be concluded that the use of new nature texts in online communication does not depend on such characteristics as gender or the frequency of communication in real life.

Then, the author analyzed the variety of new nature texts used in personal dialogues. It is noteworthy that the use of emojis is frequent, as in the case of group chats. Furthemore there is an interesting fact: memes have become the least used type of new nature texts, which probably means that the era of memes as a tool of communication is gradually ending. In addition, the authors prefer to think, that memes are giving way to stickers. It is also 
surprising, that, in some cases, voice messages make up a significant percentage of polycode communication, almost equal to the percentage of verbal messages. This fact provokes the idea that the trend of using voice messages is still at the very beginning of its development, and it is likely that in the near future the percentage of voice messages in Internet communication will increase.

Due to the fact that the use of emoji has turned out to be the most frequent phenomenon, the author analysed polycode messages containing emojis for the presence of the "Emoji + text" cases. Thus, we were trying to investigate which function is dominant: the expression of a coded reaction/emotion or the emotional enrichment of a verbal message. According to the results of the study, it was more often the emoji used in combination with text, which proves that the enrichment function is dominant.

Speaking about the function of expressing a coded reaction/emotion, we should mention that it is usual for all texts of a new nature. However, it is the most clearly shown by the iconic component, which is represented by emoji and stickers - the most popular types of new nature texts. It is noteworthy that in most dialogues, the number of cases when stickers or emojis are used to express a coded reaction/emotion is almost equal, which makes it possible to conclude that these texts of a new nature are interchangeable.

Nevertheless this study has some pecularities: the author studied the communication of the people of the same age and social status (urban dwellers of 20-25 years old and students). This fact does not allow the authors to talk about a comprehensive analysis of the phenomenon of using new nature texts in Internet communication. This analysis is more of a cross-sectional study, since it clearly reflects how young people are receiving higher education communicate online.

\section{Conclusion}

Summing up, the authors point out the fact, that in the majority of cases, the new nature texts are used to express a reaction to something. However, the main function of using such texts is the fulfillment of the verbal message with emotions and the creation of a friendly and positive atmosphere. For example, all stickers and emoji are bright and colorful images, no matter if they express negative or positive emotions. 


\section{Conflict of Interest}

The authors have no conflict of interest to declare.

\section{Acknowledgements}

This research was financially supported by the Russian Foundation for Basic Research (Grant No. 17-29-09136\20 "Multilingualism in the Era of Post-literacy: Philosophical and Cultural Studies and Methodological and Pedagogical Development of a Multilingual Education Model").

\section{Referenses:}

1. Social'nyeseti v cifrah // oficial'nyj sajt kompanii Mediaskop [Social networks in numbers // official website of MediaScope] URL: https://mediascope.net/upload/ iblock/f97/18.04.2019_Mediascope_Екатерина Курносова_РИФ+КИБ 2019.pdf (Accessed 10 May 2020)

2. Ye. I. Kazakova. Teksty novoy prirody: problemy mezhdistsiplinarnogo issledovaniya (Texts of a new nature: problems of interdisciplinary research). Psikhologicheskaya nauka i obrazovaniye. 2016. № 4 (21). pp. 102-109.

3. T. G. Galaktionova. Teksty "novoy prirody" i novaya gramotnost'. Teksty novoy prirody v obrazovatel'nom prostranstve sovremennoy shkoly. Sbornik materialov VIII mezhdunarodnoy nauchno-prakticheskoy konferentsiya "Pedagogika teksta". Pod redaktsiyey T. G. Galaktionovoy, Ye. I. Kazakovoy ("New nature" texts and new literacy. Texts of a new nature in the educational space of the modern school. Collection of materials of the VIII international scientific-practical conference "Pedagogy of text”. Edited by T. G. Galaktionova, E. I. Kazakova.). 2016. pp. 13-17.

4. M. V. Zagidullina. Mul'timodal'nost': k voprosu o terminologicheskoy opredelennosti (Multimodality: on the issue of terminological certainty). Znak: problemnoye pole mediaobrazovaniya. 2019. № 1 (31). pp. 181-188.

5. G. V. Yeyger, V.L. Yukht. K postroyeniyu tipologii tekstov (To the construction of typology of texts).Lingvistika teksta: materialy nauchnoy konferentsii MGPIIYA im. M. Toreza. M., 1974. Vol. I. pp. 103-109.

6. L. V. Dubovickaya. Fenomen kreolizovannogo teksta: avtoref. dis. ... kand. filol. Nauk [The phenomenon of creolized text. Abstract for the candidate of sciences degree thesis]. Moscow. (2013).

7. P. Celentin. Applicazionididattiche del video in Cardona, M. (a cura di) Vedere per capire e parlare, Utet, Torino. (2007). 